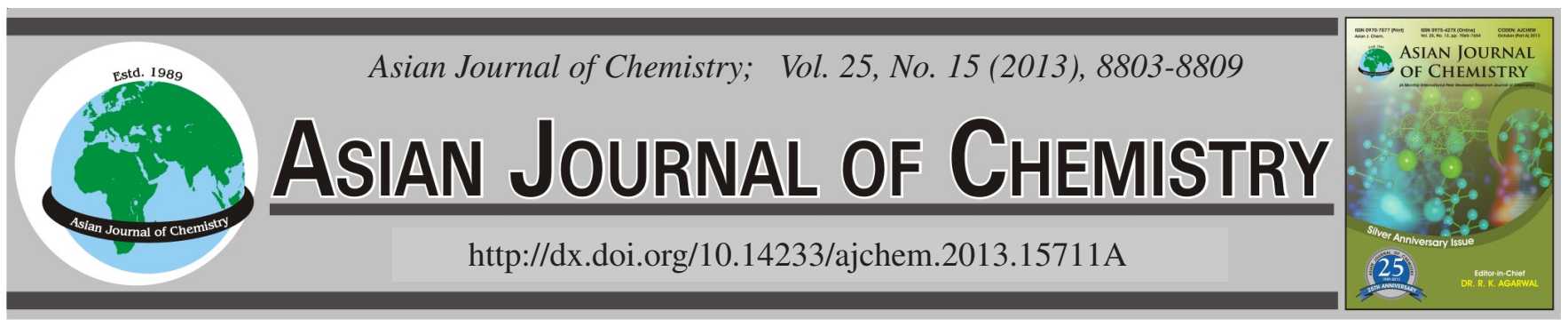

\title{
Kinetic Study and Cyclization of High Tacticity of Polyacrylonitrile Under Different Oxygen Supply Concentration
}

\author{
Li ZHANG ${ }^{1,2}$, Zhiling LiU ${ }^{3}$, YongQIANG DAi ${ }^{1}$ and QIFANG Li ${ }^{1}{ }^{*}$
}

${ }^{1}$ State Key Laboratory of Chemical Resource Engineering, Beijing University of Chemical Technology, Beijing 100029, P.R. China ${ }^{2}$ Northwest Research Institute of Chemical Industry, Xi'an 710600, P.R. China

${ }^{3}$ Research institute of YangChang Petroleum (Group) Co., Ltd., Xi'an 710075, P.R. China

*Corresponding author: Tel: +86 15991278172; E-mal: leeger_zl@163.com

(Received: 1 May 2013;

Accepted: 29 August 2013)

AJC-14053

\begin{abstract}
Isotactic polyacrylonitrile with triad isotacticity of 0.53 was successfully synthesized by using dialkylmagnesium as initiator. The effects of oxygen concentrating on chemical evolutions and thermal properties of iso-polyacrylonitrile were studied by Fourier transform infrared spectroscopy and thermal gravimetric analysis at different concentration $(0,20,50$ and $80 \mathrm{vol} . \%)$. Activation energy of thermal stabilization was obtained under non-isothermal conditions by using iso-conversional methods. The results showed that the amount of un-cyclized nitrile groups increased with oxygen concentration. This indicated that the cyclization was affected by oxygen concentration. Two stages and a large residue mass of iso-polyacrylonitrile pyrolysis during oxidation were detected in the oxygen-containing atmosphere. The activation energies were calculated by Kissinger-Akahira-Sunose (KAS) and Flynn-Wall-Ozawa (FWO) iso-conversional method under different oxygen concentration varying from 0 to $80 \%$.
\end{abstract}

Key Words: Polyacrylonitrile, High tacticity, Oxygen concentration, Thermal stabilization, Activation energy.

\section{INTRODUCTION}

Polyacrylonitrile (PAN) has been accepted as the most suitable precursor for producing high performance carbon fibers with excellent properties such as low density, high stiffness and strength and good resistance to chemical and environmental $^{1-4}$. However, the production of polyacrylonitrile-based carbon fiber, including precursor spinning, thermal stabilization and carbonization, is a complicated process. The properties of the reluctant carbon fiber are significantly influenced by the parameters of each process, particularly the precursor fibers and thermal stabilization. High performance carbon fibers can only be produced depending on fine precursor fibers with excellent properties and optimized pre-oxidation.

To improve the mechanical properties of the precursor fibers and reduce both the induction period and rate of heat release during stabilization have drawn much attention in earlier researches ${ }^{5-7}$. The stereoregularity of polyacrylonitrile, which was beneficial to cyclization during stabilization, was rarely studied ${ }^{8}$. Nowadays, high stereoregularity of polyacrylonitrile could be obtained through acrylonitrile-urea canal polymerization, which was initiated, by $\gamma$-ray irradiation, matrix-anionic-polymerization and etc. ${ }^{9-11}$. The iso-polyacrylonitrile precursor with high stereoregularity was an effective way to obtain high performance carbon fiber.
Meanwhile, pre-oxidation was an essential and the most time-consuming step to produce carbon fiber. During this process many chemical reactions were involved including cyclization, dehydrogenation, aromatization, oxidation and crosslinking which could result in the formation of conjugated ladder structure with high infusibility and stability ${ }^{12}$. These physical and chemical changes depended strongly on some thermal stabilization parameters such as temperature, duration time, heating rate and stretching ratios ${ }^{13}$.

Additionally, lots of work has been done on the kinetic study of the elemental reactions. Fitzer and Müler studied the rate of homo-polymer polyacrylonitrile fiber cyclization in nitrogen and air using DTA and concluded that cyclization could be described by a first order kinetic scheme ${ }^{14}$. Morita et al. and Dunham studied the kinetics of homo-polymer and copolymer polyacrylonitrile cyclization by infrared analysis ${ }^{15}$. By far most of researchers have focused on kinetic study of the elemental reactions and the most of the experiments were performed in certain atmospheres such as nitrogen or air. Considering the complicated reactions during pre-oxidation, the mixed gas of oxygen and nitrogen, the effect of atmosphere on cyclization rate and the kinetic parameters had been rarely reported.

In the present work, the effect of atmosphere with oxygen concentration of $0,20,50$ and $100 \%$ on the cyclization rate and kinetic parameters was studied. Structural evolutions of 
isothermal treatment of high iso-tacticity polyacrylonitrile under different atmosphere were investigated by Fourier transform infrared spectroscopy. The effect of oxygen during stabilization of iso-polyacrylonitrile was discussed. The activation energies in different atmosphere were calculated by differential scanning calorimetry data at different heating rate of $5,10,15^{\circ} \mathrm{C}$, using iso-conventional method, viz. Kissinger-Akahira-Sunose (KAS) and Flynn-Wall-Ozawa (FWO) method.

\section{EXPERIMENTAL}

A $100 \mathrm{~mL}$ four-necked flask equipped with stirrer, dropping funnel, condenser, two-way cock and thermometer was needed for the polymerization. The flask should be flushed with dry nitrogen for $5 \mathrm{~min}, 0.053 \mathrm{~g}$ (1,4-cyclohexanediol) and $40 \mathrm{~mL}$ xylene were added. After dissolving 1,4-cyclohexanediol completely at $130{ }^{\circ} \mathrm{C}$, the initiator $\left(n-\mathrm{C}_{6} \mathrm{H}_{13}\right)_{2} \mathrm{Mg}$ as $n$-heptane solution was added into flask with stirring, white solvent-insoluble substances formed immediately. Keeping the solution with initiator at $138^{\circ} \mathrm{C}$ for $15 \mathrm{~min}$, then $5 \mathrm{~mL}$ acetonitrile was added dropwise with stirring. The polymerizations were allowed for $7 \mathrm{~h}$ and then $\mathrm{HCl}$ and $\mathrm{CH}_{3} \mathrm{OH}$ solution as polymerization terminator were added dropwise with stirring. After being cooled to room temperature, the solution was collected by filtration through a glass filter (G3 grade) and successively washed with acetone, water and acetone. After dried in vacuum for $24 \mathrm{~h}$, white polyacrylonitrile powder was obtained.

Isothermal treatment of polyacrylonitrile powder was conducted at different temperature $\left(200,220,250\right.$ and $\left.280{ }^{\circ} \mathrm{C}\right)$ in a precision controlled tube furnace with temperature accuracy of $1{ }^{\circ} \mathrm{C}$. After the temperature in furnace reached to the settled temperature, iso-polyacrylonitrile was placed into the furnace. Pre-oxidation reactions started immediately and samples with different reaction degree were obtained at various reaction times $(5,10,15,30$ and $60 \mathrm{~min})$.

FTIR spectroscopy: FTIR spectra of samples were recorded (Nicolet-210, US). As reaction proceeds, nitrile groups with an absorbance at $2243 \mathrm{~cm}^{-1}$ reacted and produced cyclized units containing $-\mathrm{C}=\mathrm{N}$ - and $-\mathrm{C}=\mathrm{C}$ - groups, whose $\mathrm{ab}$ sorbance were detected at $1595 \mathrm{~cm}^{-1}$. Extent of cyclization was estimated from the infrared spectrum by following formula with unreacted nitrile group fraction.

Residual nitrile group fraction (RCNF):

$$
\mathrm{RCNF}=\frac{\mathrm{I}_{2240 \mathrm{~cm}^{-1}}}{I_{2240 \mathrm{~cm}^{-1}}+\mathrm{f} \times \mathrm{I}_{1590 \mathrm{~cm}^{-1}}}
$$

where, $\mathrm{I}_{2243 \mathrm{~cm}^{-1}}$ is the absorption of nitrile groups, $\mathrm{I}_{1595 \mathrm{~cm}^{-1}}$ is the absorption of $-\mathrm{C}=\mathrm{C}$ - and $-\mathrm{C}=\mathrm{N}$ - groups and $\mathrm{f}$ is the ratio of nitrile group and cyclized group absorptivity constants. In general, $f=0.29$, which has been previously derived in the literatures ${ }^{16,17}$.

DSC measurement: DSC measurements were carried out using calorimeter (Netzsch-STA449C, Germany). A 5 mg isopolyacrylonitrile specimen was placed into the coil, which was made of aluminum-based alloy. Empty coil was used as a reference. The specimen was heated in the instrument with different heating rate of $5,10,15^{\circ} \mathrm{C} / \mathrm{min}$ from $45-450{ }^{\circ} \mathrm{C}$ in different atmosphere with a flow of $40 \mathrm{~mL} / \mathrm{min}$.
Characteristic of isotacticity of polyacrylonitrile: ${ }^{13} \mathrm{C}$ NMR spectra at $75.47 \mathrm{MHz}$ were recorded on a Bruker MSL 300 (Karlsruhe, Baden-Wrttemberg, Germany) instrument in 5 wt. \% solution in deuterated dimethylsulfoxide at $25{ }^{\circ} \mathrm{C}$. The setup parameters chosen were: flip angle $30^{\circ}$, repetition time $2 \mathrm{~s}$, the spectra were calibrated at the central signal of DMSO- $d_{6}$ at $39.5 \mathrm{ppm}$.

A triad tacticity $[(\mathrm{mm}),(\mathrm{mr})$ and $(\mathrm{rr})[\mathrm{m}$ and $\mathrm{r}$ mean meso and racemo diad sequences, respectively] was determined on the basis of the Schaefer's assignment by ${ }^{13} \mathrm{C}$ nuclear magnetic resonance spectroscopy spectra, from the ratio of intensities for the three methane carbon peaks (26.9 ppm for mm, 27.4 ppm for $\mathrm{mr}$ and $27.9 \mathrm{ppm}$ for rr methane carbon) in the ${ }^{13} \mathrm{C}$ NMR spectrum ${ }^{18,19}$.

By calculating the mathematical area of three peaks, the tacticity of the polymer was obtained: $53.4 \%$ ( $\mathrm{mm}), 19.47 \%$ ( $\mathrm{mr}$ ), $27.13 \%$ (rr), respectively. Higher the value of $\mathrm{mm}$ is , more nitrile groups exist in the same plane, which greatly affects thermal stabilization of the polymer. Fig. 1 is the ${ }^{13} \mathrm{C}$ NMR spectrum of high isotacticity of polyacrylonitrile.

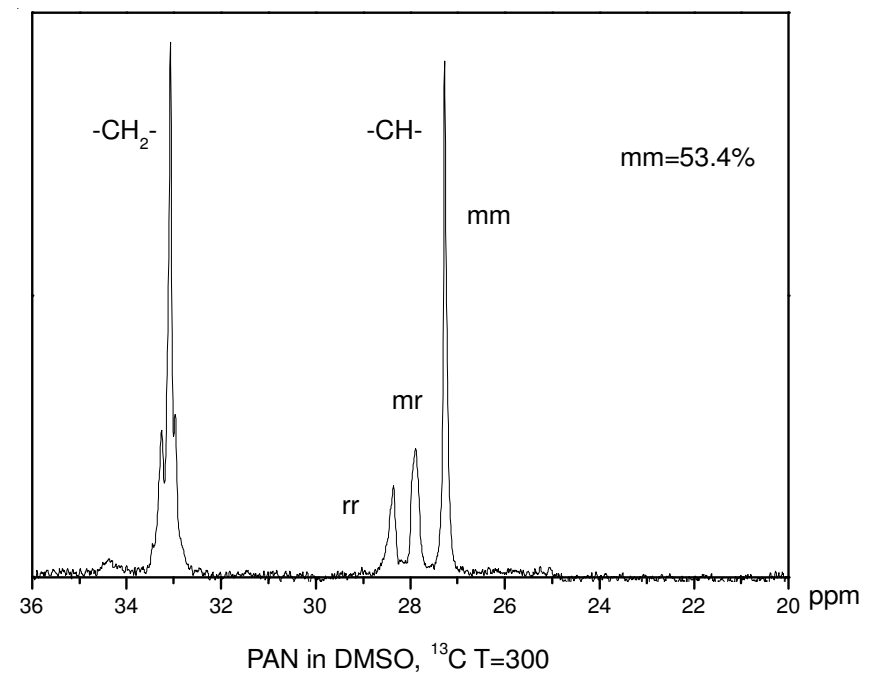

Fig. $1 .{ }^{13} \mathrm{C}$ NMR spectrum of high isotacticity of polyacrylonitrile (PAN)

\section{RESULTS AND DISCUSSION}

Effect of atmosphere on cyclization: In order to investigate the effect of atmosphere on cyclization reactions, the isothermal treatment was performed at $250^{\circ} \mathrm{C}$, for different times $(0,10,20,30,60,120 \mathrm{~min})$ at different oxygen concentration to study the variation of the rate of nitrile cyclization.

Fig. 2 shows the changes occurring in the IR spectra from $4000-400 \mathrm{~cm}^{-1}$ for iso-polyacrylonitrile isothermal treatment at $250{ }^{\circ} \mathrm{C}$ under atmosphere with $\mathrm{N}_{2}$ content of $50 \%$ for 10 , 20, 60, $120 \mathrm{~min}$, respectively. The band at $2243 \mathrm{~cm}^{-1}$ corresponds to $\mathrm{CN}$ stretching vibration of acrylonitrile unit in the polymer chain, absorption bands at 2939 and $1454 \mathrm{~cm}^{-1}$ were assigned to $\mathrm{CH}_{2}$ stretching and $\mathrm{CH}$ bending vibration, respectively. The assignments of some other absorption bands are given as follows: $1366 \mathrm{~cm}^{-1}$ (bending of the aliphatic $\mathrm{CH}$ group), $1227 \mathrm{~cm}^{-1}$ (twist vibration of $\left.-\mathrm{CH}_{2}\right)^{20}$. Minor changes could be observed in the first $20 \mathrm{~min}$ from IR spectra in Fig. 2(a-b). The weak absorption at $1632 \mathrm{~cm}^{-1}$ was probably due to termination by disproportionation, which was confirmed by 


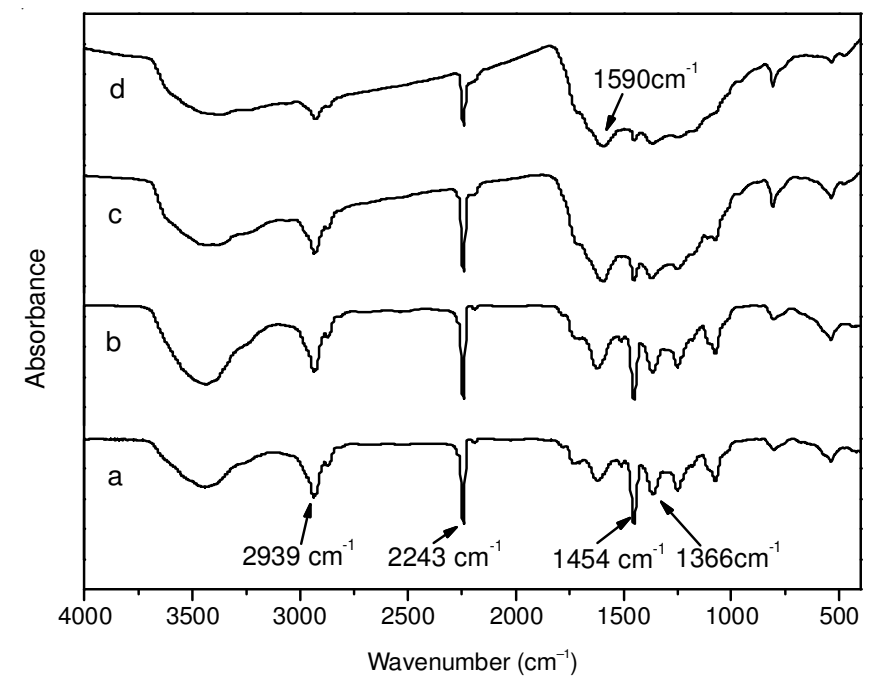

Fig. 2. IR spectra of iso-polyacrylonitrile isothermal treatment at $250{ }^{\circ} \mathrm{C}$ under atmosphere of $50 \% \mathrm{~N}_{2}$ for (a) 10; (b) 20; (c) 60; (d) $2 \mathrm{~h}$

by the discoloration of very dilute bromine water. The broad absorption between $3520-3200 \mathrm{~cm}^{-1}$ is correspond to vibration of -OH of unsaturated water ${ }^{21}$. As stabilization proceeded, the nitrile peak at $2243 \mathrm{~cm}^{-1}$ and the peak due to $-\mathrm{CH}_{2}$ bending in open chain at $1454 \mathrm{~cm}^{-1}$ decrease slightly in intensity for the first $0.5 \mathrm{~h}$ shown in Fig. 2(a-b). Meanwhile, the peak due to the aromatized structure at 1595 and $1366 \mathrm{~cm}^{-1}$ increased in intensity with an enhancement of extent of stabilization ${ }^{22}$. As shown in Fig. 2(c-d), a wide shoulder band appears at 1730 $\mathrm{cm}^{-1}$ due to $\mathrm{C}=\mathrm{O}$ is assigned to stretching of ketone, due to oxygen up taken reaction. After stabilized for $2 \mathrm{~h}$, the final product still had some nitrile band left shown in Fig. 2(d). However, the band at 2243 and $1454 \mathrm{~cm}^{-1}$ had dramatically decreased comparing to the previous ones. The result indicated that the co-existence of a ladder structure with conjugated unsaturated bonds, coupled with linear structure polyacrylonitrile polymer chains.

Fig. 3 presents the spectra of iso-polyacrylonitrile stabilized at $250{ }^{\circ} \mathrm{C}$ for $2 \mathrm{~h}$ under different oxygen concentration, the changes in the spectrum can be observed. Absorption of nitrile at 2243 and $2939 \mathrm{~cm}^{-1}$ decreased continuously, whereas the intensity of the peak at $1595 \mathrm{~cm}^{-1}$ increased enormously as the decrease of oxygen concentration, which implied at low concentration of oxygen, more nitrile group remained at the same treated time and temperature, combined with the absorption at the band of $\mathrm{C}=\mathrm{C}$ and $\mathrm{C}=\mathrm{N}$ could conclude that oxygen concentration is one of crucial factors to affect the structural evolution.

According to the formula (1), residual $\mathrm{CN}$ fractions were calculated (Fig. 4) using the intensity at 2243 and $1595 \mathrm{~cm}^{-1}$, which can measure the extent of cyclization and comparison for different reaction environment on cyclization. From Fig. 4, the presence of oxygen during stabilization had a significant impact on the rate of cyclization. The residual nitrile groups in the initial step was almost the same for different oxygen concentration, however, from 20 min to the end of the reaction, the residual nitrile groups was lower for the nitrogen than the oxygen containing environments and different amount of nitrile groups remained even isothermal treated for a long time. The finding of the oxygen contain atmosphere slowed the rate

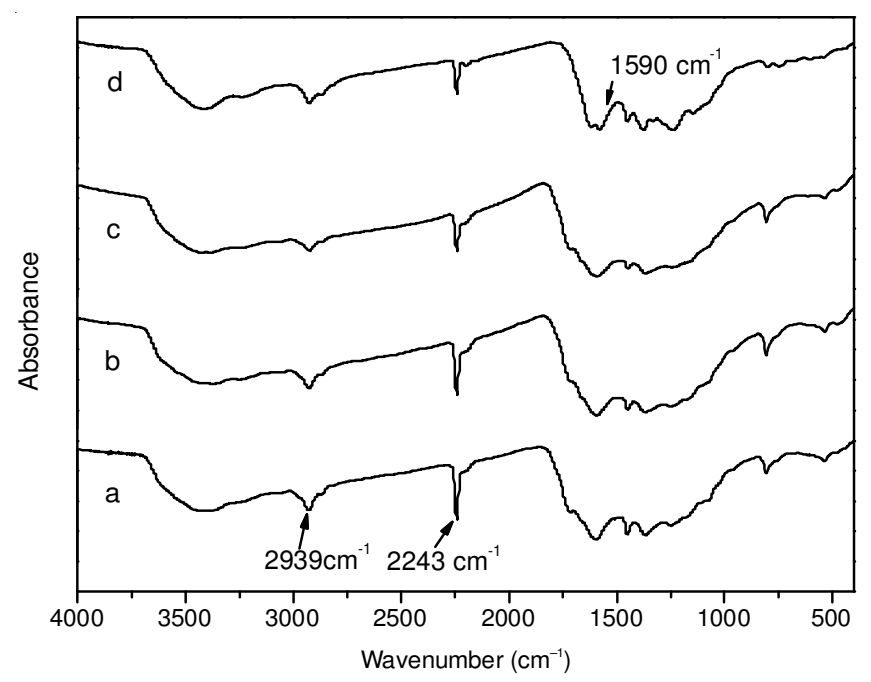

Fig. 3. IR spectra of iso-polyacrylonitrile isothermal treatment at $250{ }^{\circ} \mathrm{C}$ for $2 \mathrm{~h}$ under atmosphere of (a) $100 \%$; (b) $50 \%$; (c) $20 \%$; (d) $0 \%$ of $\mathrm{O}_{2}$

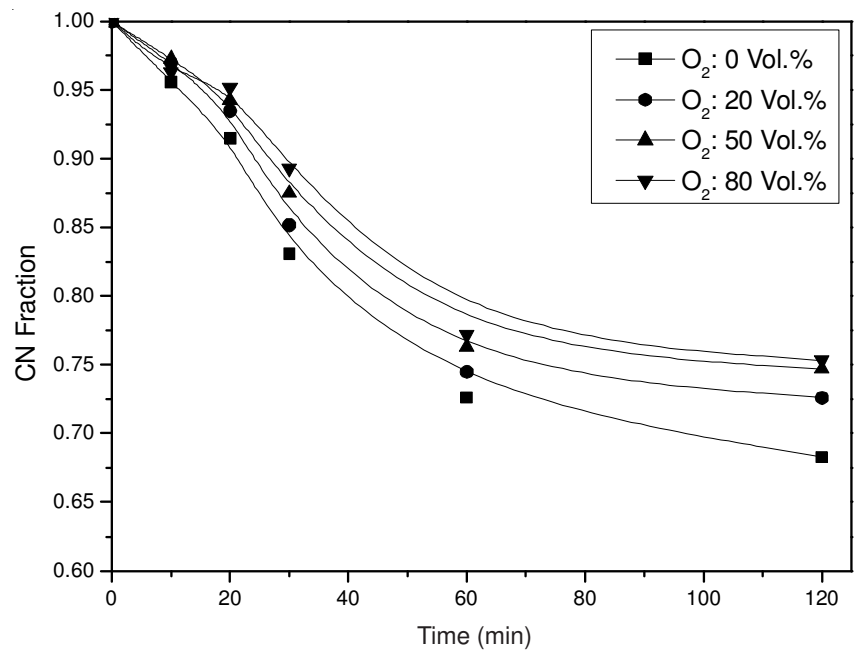

Fig. 4. Residual nitrile groups of high tacticity polyacrylonitrile under different atmospheres

of cyclization indicated that the oxygen has an inhibiting effect on cyclization of iso-polyacrylonitrile and the retarding effect of oxygen may be attributed to interference of initiation by oxygen, for the cyclization of polyacrylonitrile was thought to be initiated by a radical mechanism and the propagation of cyclization may be terminated by the scavenging of radical intermediates formed during initiation under the oxygen containing atmosphere ${ }^{23}$.

Thermal study: Fig. 5 shows the weight loss (TG) of iso-polyacrylonitrile during stabilization under different atmospheres from $100-450{ }^{\circ} \mathrm{C}$ at heating rate of $5^{\circ} \mathrm{C} / \mathrm{min}$. It can be seen that two individual stages can be distinguished. The first stage was from room temperature to 293, 291, 287 and $285^{\circ} \mathrm{C}$ for oxygen concentration of $0,20,50$ and $80 \%$, respectively, corresponded to a loss of moisture and the minor volatile gases, the temperature of initial devolatilization decreased with oxygen concentration. The second stage was the rest of stabilization and was characterized by a significant weight loss of 30.39, 23.44, 21.08 and $27.04 \%$ occurred at the oxygen concentration of $0,20,50$ and 80 vol. \%, respectively, corresponded to large amount of chain secession, 


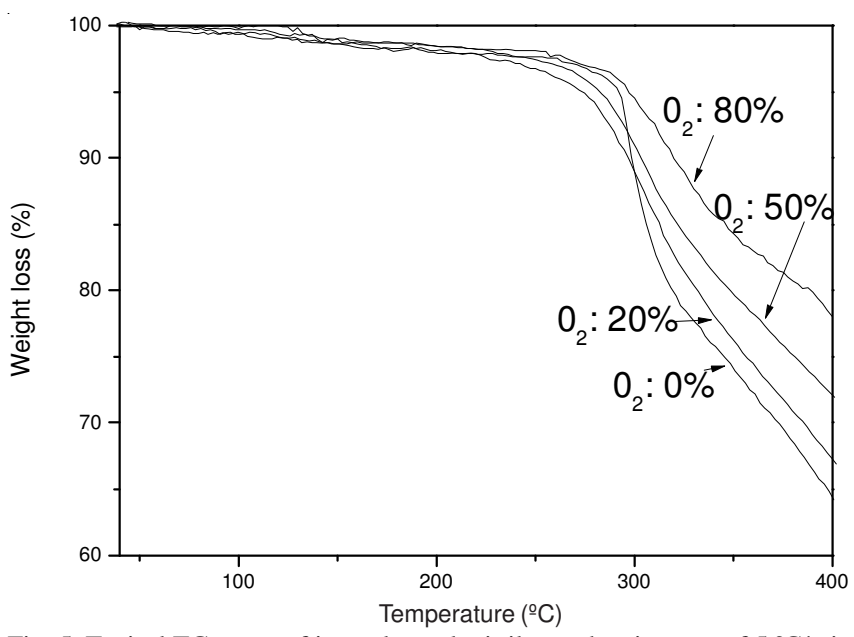

Fig. 5. Typical TG curve of iso-polyacrylonitrile at a heating rate of $5^{\circ} \mathrm{C} / \mathrm{min}$

dehydrogenation and cyclization and oxidation for the oxygencontaining atmosphere. In the second stage, greater loss occurred and decomposed gases such as $\mathrm{HCN}, \mathrm{NH}_{3}$ and $\mathrm{CO}_{2}$ when stabilized in free oxygen atmosphere. In the oxygencontaining atmosphere, oxidation can also slow down the weight loss comparing with the abrupt pyrolysis happened in nitrogen. However, the scavenging of radical intermediates can retards the propagation of cyclization in oxygen-containing atmospheres and the retarding effect of oxygen is more notable which causes the less oxidation reaction during stabilization as oxygen concentration increasing, resulting in the greater weight loss in higher oxygen concentration.

Kinetic study from DSC data at different heating rate under different atmospheres: There are some methods to evaluate activation energy of pre-oxidation by the value of cyclization index and aromatization through FTIR and X-ray diffraction by isothermal treatment of iso-polyacrylonitrile. There are some short comings of each method which can only evaluate the elementary reaction during the pre-oxidation. However such methods are not suitable for the pre-oxidation involving some elementary reactions. The iso-conversional methods involving Flynn-Wall-Ozawa (FWO) and KissingerAkahira-Sunose (KAS) methods were used for analysis the kinetic of pre-oxidation by means of DSC dates of iso-polyacrylonitrile at different heating rate $^{24-27}$.

The DSC curves of iso-polyacrylonitrile treated from room temperature to $450{ }^{\circ} \mathrm{C}$ at heating rate of 5,10 and $15^{\circ} \mathrm{C} / \mathrm{min}$ under with oxygen concentration of $20 \mathrm{vol}$. \% was shown in Fig. 6. The rest of DSC curves obtained under different atmosphere performed the same trend. The exothermic peaks wholly shifted to a higher temperature with the peak temperature were $302.5,312$ and $319.8^{\circ} \mathrm{C}$, respectively and the exothermic peaks became stronger and stronger. This is because polymer had enough time to take fully reaction, thermal effect and thermal inertia of the reaction increase with increasing heating temperature, samples could not be heated in time, so the cyclization only takes place at higher temperature and the exothermic peaks shifted to higher temperature.

DSC analyses were performed at different heating rate. The conversionáat any time (t) was obtained from the relation:

$$
\alpha=\frac{\mathrm{H}_{\mathrm{t}}}{\Delta \mathrm{H}}
$$

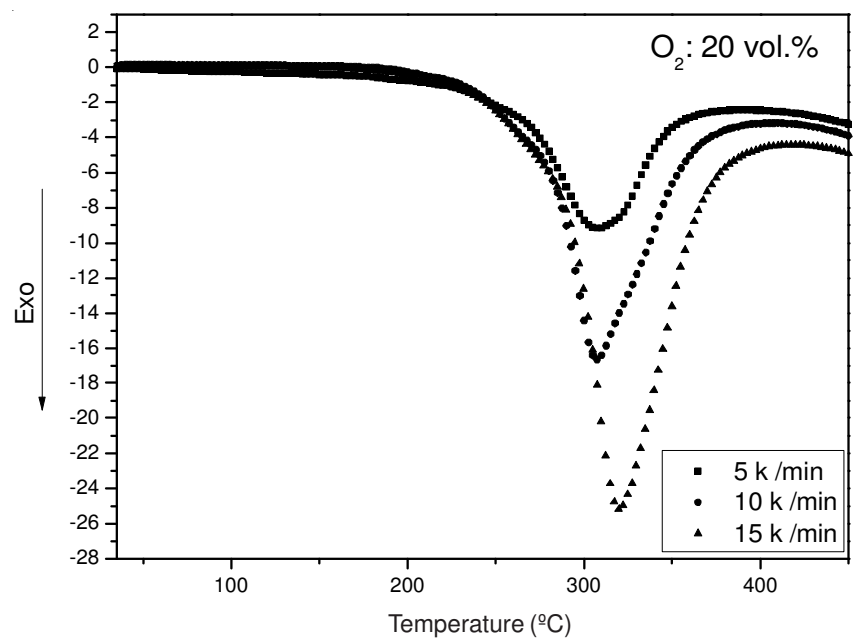

Fig. 6. DSC cursors of iso-polyacrylonitrile at different heating rate under atmosphere with oxygen concentration of $20 \mathrm{vol}$. \%

where $\mathrm{H}_{t}$ is the fractional heat of reaction at $\mathrm{t}$ min and $\mathrm{H}$ is the total enthalpy. The rate of conversion, is the linear function of temperature-dependent rate constant, $\mathrm{k}(\mathrm{T})$ and the temperatureindependent function of conversion, $f(\alpha)$,

$$
\frac{\mathrm{d} \alpha}{\mathrm{dt}}=\mathrm{k}(\mathrm{T}) \mathrm{f}(\alpha)
$$

where $t(s)$ is time, $T(K)$ is the absolute temperature, $k(T)$ can be described by the Arrhenius equation:

$$
\mathrm{k}=\mathrm{A} \exp \left(-\frac{\mathrm{E}}{\mathrm{RT}}\right)
$$

where $\mathrm{A}\left(\mathrm{s}^{-1}\right)$ is pre-exponential, $\mathrm{E}\left(\mathrm{kj} \mathrm{mol}^{-1}\right)$ is the activation energy, $\mathrm{R}\left(\mathrm{kj} \mathrm{mol}^{-1} \mathrm{k}^{-1}\right)$ is the universal gas constant. The function $f(\alpha)$ is expressed as:

$$
f(\alpha)=(1-\alpha)^{n}
$$

where $\mathrm{n}$ is the reaction order, so the formula $2-5$ can be modified to:

$$
\frac{\mathrm{d} \alpha}{\mathrm{dt}}=\mathrm{A} \exp \left(-\frac{\mathrm{E}}{\mathrm{RT}}\right)(1-\alpha)^{\mathrm{n}}
$$

The heating rate $\Phi$ can be described as $\phi=\frac{\mathrm{dT}}{\mathrm{dt}}$, eqn. 6 could be transferred to:

$$
\frac{\mathrm{d} \alpha}{(1-\alpha)^{\mathrm{n}}}=\frac{\mathrm{A}}{\phi} \exp \left(-\frac{\mathrm{E}}{\mathrm{RT}}\right) \mathrm{dT}
$$

The integration function of eqn. 7 is shown as

$$
\mathrm{g}(\alpha)=\int_{0}^{\alpha} \frac{\mathrm{d} \alpha}{(1-\alpha)^{\mathrm{n}}}=\frac{\mathrm{A}}{\phi} \int_{\mathrm{T}_{0}}^{\mathrm{T}} \exp \left(-\frac{\mathrm{E}}{\mathrm{RT}}\right) \mathrm{dT}
$$

where $\mathrm{T}_{0}$ is the starting temperature, the Kissinger-AkahiraSunose (KAS), Flynn-Wall-Ozawa (FWO) formulae can be obtained by transforming eqn. 8 into eqns. 9 and 10:

$$
\ln \left(\frac{\phi}{\mathrm{T}^{2}}\right)=\ln \left[\frac{\mathrm{AR}}{\mathrm{Eg}(\alpha)}\right]-\frac{\mathrm{E}}{\mathrm{RT}}
$$

$$
\log \phi=\log \left[\frac{\mathrm{AE}}{\operatorname{Rg}(\alpha)}\right]-2.315-0.4567 \frac{\mathrm{E}}{\mathrm{RT}}
$$


The advantage of the two methods is activation energy can be evaluated without knowing the reaction model and mechanism of the pre-oxidation. So the kinetic parameters can be evaluated by these methods without assuming reaction model but the peak temperatures of DSC analysis at different heating rate ${ }^{28}$.

From the DSC curves under different heating rate and atmosphere, coupled with the conversion $(\alpha)$ at any time $(\mathrm{t})$ (only oxygen concentration of 20 vol. \% was shown in Fig. $7)$, the activation energy at different conversion can be calculated by the two methods. Plots of $\ln \Phi, \ln \left(\Phi / \mathrm{T}^{2}\right)$ at various conversions $\alpha$ against 1/T should be straight lines according to the eqns. 9 and 10. From the plot of lines depicted in Figs. 8-11 from DSC data at different conversion by the two methods in various atmospheres can estimate apparent activation energies.

As shown in Table-1, the activation energies at different conversion and their average values were calculated through the KAS and FWO methods. Meanwhile, the high linear correlation coefficients greater than 0.99 of all plots, which were also listed in the table, suggested the results of determination of activation energies were credible. The activation energies calculated by the two methods were very close to each other, so the average values of $124.9,176.1,147.5$ and $251.5 \mathrm{Kj} / \mathrm{mol}$ could be considered as activation energies of stabilization for the oxygen concentration of $0,20,50,80 \mathrm{vol} \%$, respectively.

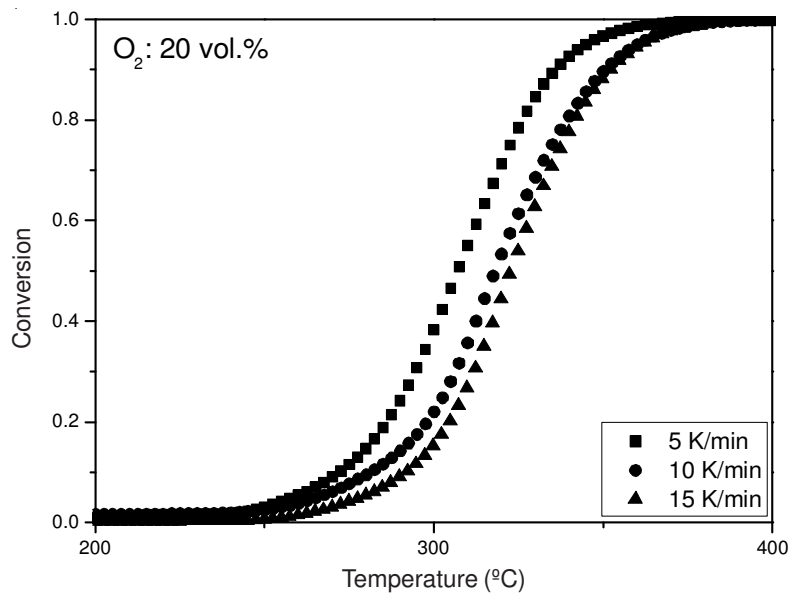

Fig. 7. Conversion obtained from the DSC data of iso-polyacrylonitrile at different heating rate under atmosphere with oxygen concentration of 20 vol. $\%$

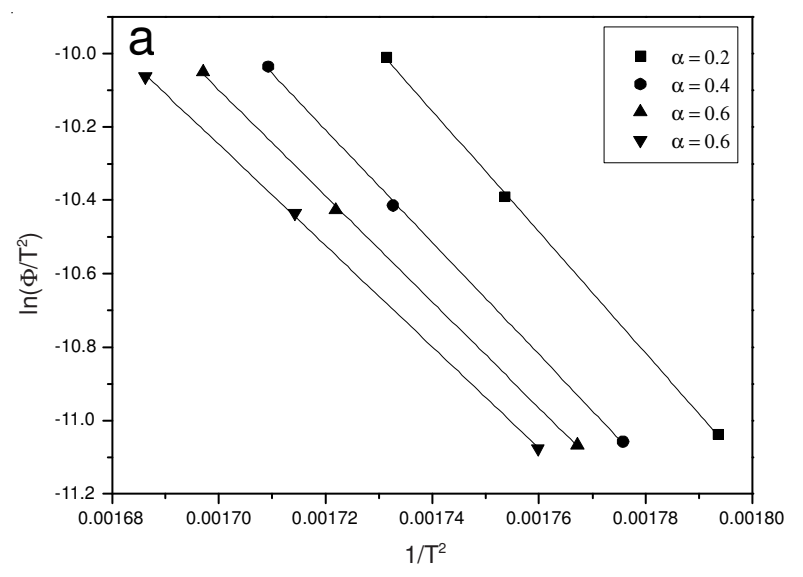

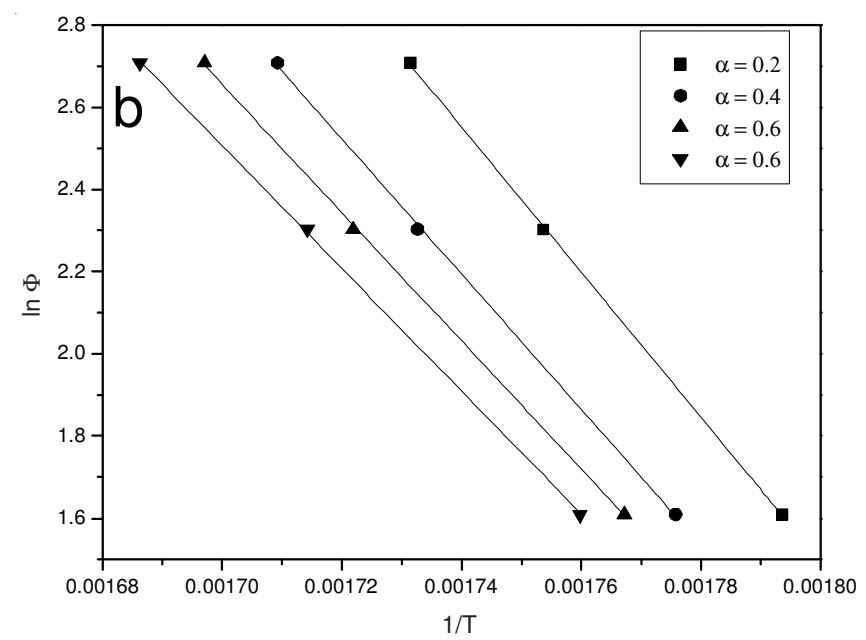

Fig. 8. Plots for determination of activation by (a) KAS; (b) FWO methods at different conversion in the atmosphere with oxygen concentration of $0 \%$
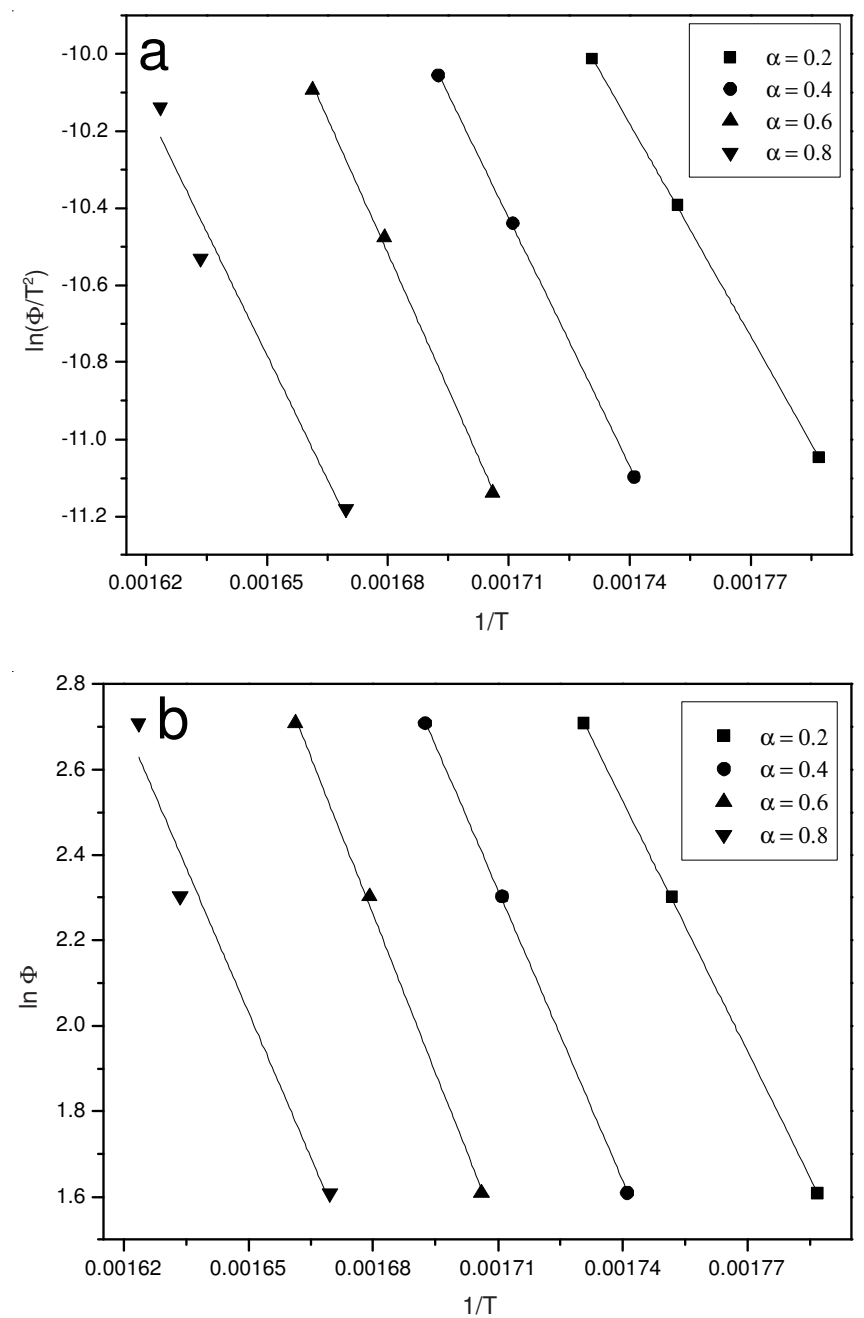

Fig. 9. Plots for determination of activation by (a) KAS; (b) FWO methods at different conversion in the atmosphere with oxygen concentration of $20 \%$

From the curve of activation energies varied different oxygen concentration was plotted in Fig. 12. As the oxygen concentration increased, the apparent activation energy first increased with oxygen concentration, then a slight decrease from $20-50 \%$. At last a significant increase till $80 \%$ of oxygen 


\begin{tabular}{|c|c|c|c|c|c|}
\hline \multirow{3}{*}{ Atmosphere } & \multicolumn{5}{|c|}{$\begin{array}{l}\text { TABLE-1 } \\
\text { ACTIVATION ENERGIES OBTAINED BY DSC DATA AT DIFFERENT HEATING RATES }\end{array}$} \\
\hline & \multirow{2}{*}{ Conversion $(\alpha)$} & \multicolumn{2}{|c|}{ KAS } & \multicolumn{2}{|c|}{ FWO } \\
\hline & & $\mathrm{E}(\mathrm{Kj} / \mathrm{mol})$ & $\mathrm{R}^{2}$ & $\mathrm{E}(\mathrm{Kj} / \mathrm{mol})$ & $\mathrm{R}^{2}$ \\
\hline \multirow{5}{*}{$\mathrm{O}_{2}: \mathrm{N}_{2}=0: 100$} & 0.2 & 137.30 & 0.999959 & 139.53 & 0.9996 \\
\hline & 0.4 & 127.43 & 0.99918 & 130.24 & 0.99926 \\
\hline & 0.6 & 120.18 & 0.99935 & 123.40 & 0.99942 \\
\hline & 0.6 & 114.70 & 0.99954 & 118.25 & 0.99964 \\
\hline & Average & 124.90 & - & 127.86 & - \\
\hline \multirow{5}{*}{$\mathrm{O}_{2}: \mathrm{N}_{2}=20: 80$} & 0.2 & 153.06 & 0.99981 & 154.53 & 0.9984 \\
\hline & 0.4 & 178.53 & 0.99907 & 178.97 & 0.9963 \\
\hline & 0.6 & 194.90 & 0.99749 & 194.73 & 0.99775 \\
\hline & 0.8 & 178.02 & 0.94076 & 178.88 & 0.9467 \\
\hline & Average & 176.13 & - & 176.78 & - \\
\hline \multirow{5}{*}{$\mathrm{O}_{2}: \mathrm{N}_{2}=50: 50$} & 0.2 & 136.45 & 0.999959 & 146.94 & 0.9996 \\
\hline & 0.4 & 146.31 & 0.99918 & 145.87 & 0.99926 \\
\hline & 0.6 & 148.08 & 0.99935 & 147.39 & 0.99942 \\
\hline & 0.8 & 159.36 & 0.99954 & 142.13 & 0.99964 \\
\hline & Average & 147.55 & - & 145.58 & - \\
\hline \multirow{5}{*}{$\mathrm{O}_{2}: \mathrm{N}_{2}=80: 20$} & 0.2 & 163.63 & 0.999959 & 159.93 & 0.9996 \\
\hline & 0.4 & 175.78 & 0.99918 & 176.23 & 0.99926 \\
\hline & 0.6 & 229.72 & 0.99935 & 227.68 & 0.99942 \\
\hline & 0.6 & 234.58 & 0.99954 & 232.48 & 0.99964 \\
\hline & Average & 200.93 & - & 199.08 & - \\
\hline
\end{tabular}
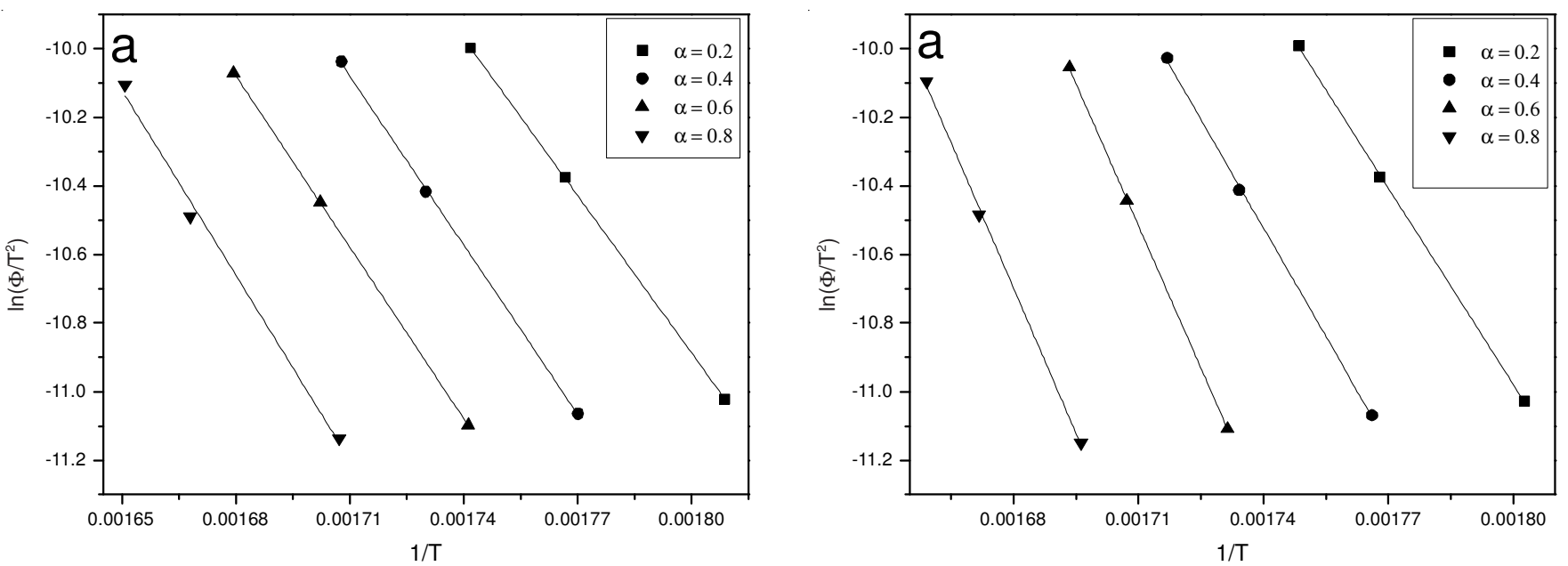

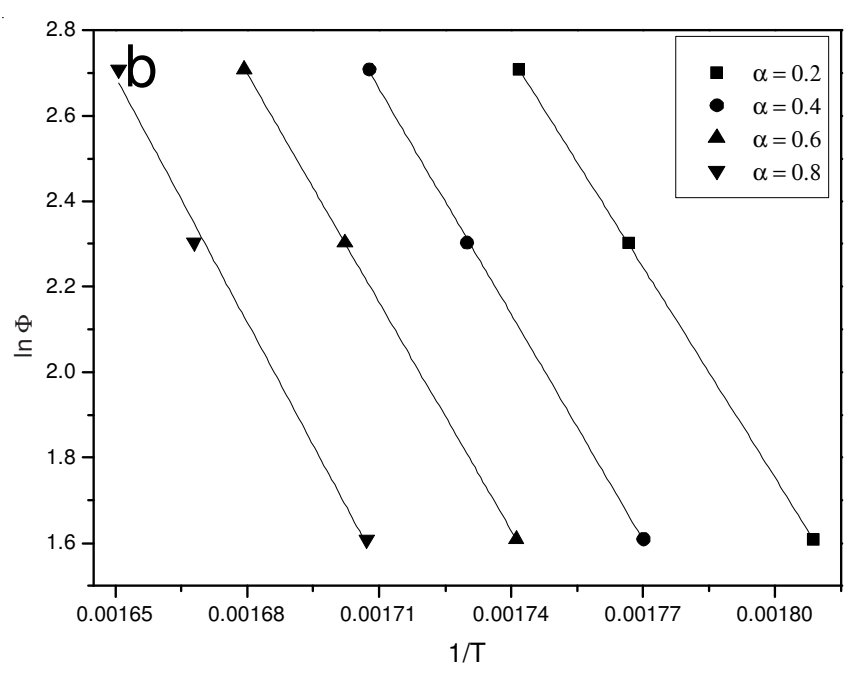

Fig. 10. Plots for determination of activation by (a) KAS; (b) FWO methods at different conversion in the atmosphere with oxygen concentration of $50 \%$

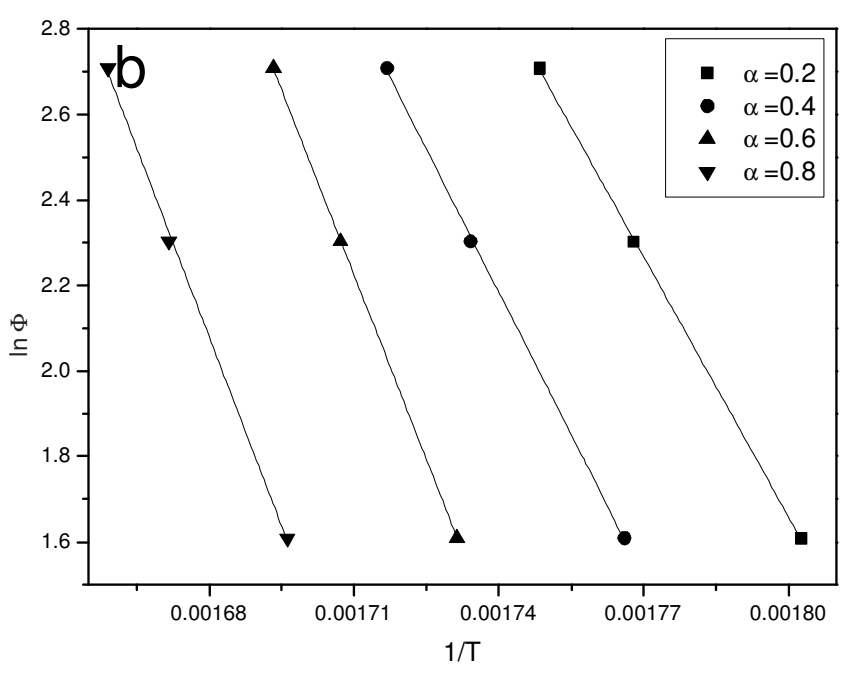

Fig. 11. Plots for determination of activation by (a) KAS; (b) FWO methods at different conversion in the atmosphere with oxygen concentration of $80 \%$ 


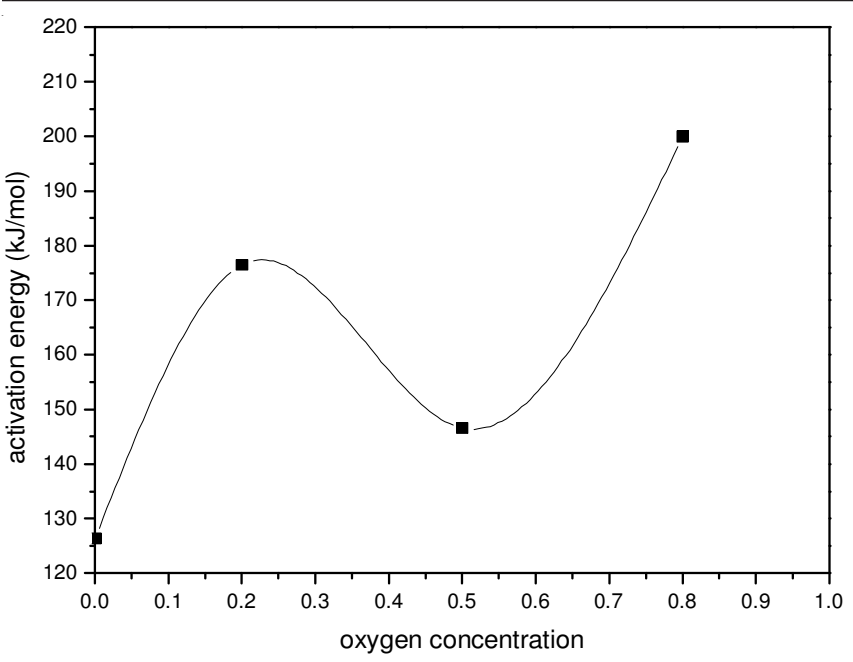

Fig. 12. Curve of activation energy varied the oxygen concentration

concentration. As the concentration increased, exothermal of oxidation during stabilization increased for the ladder structure of the oxygen-contained carbonyl group in oxygen atmosphere. Meanwhile, the retarding effect of oxygen for the termination of radical intermediates also increased. So the co-effects of oxidation and retarding affect the apparent activation energy under different oxygen-containing atmosphere ${ }^{29}$. Under the low concentration of oxygen from 0 to $20 \%$, the effect of retarding is dominant so the apparent activation energies increased with concentration; the exothermal for oxidation increased significantly when oxygen concentration increased from $20-50 \%$ and the effect of oxidation prevailed which resulted in a lower activation energy. However, when concentration is larger than $50 \%$, the increase of exothermal is very slight and the oxidation effect is weakened. The retarding effect of oxygen is obvious, which results in a increase of activation from oxygen concentration of 50-80\%.

\section{Conclusion}

High iso-tacticity of polyacrylonitrile was synthesized dialkylmagnesium $\left(\mathrm{R}_{2} \mathrm{Mg}\right)$ as initiator. Isothermal treatment of iso-polyacrylonitrile was performed at $250{ }^{\circ} \mathrm{C}$ under different oxygen concentration. The oxygen inhibiting effect for the scavenging of radical mechanism propagation of polymerization was investigated by the FTIR spectra by using the parameter of the amount of residual nitrile groups. Two stages can be distinguished during the heating process by the TG analysis for the moisture and pyrolysis process during formation of cyclized structure, the mass loss of the oxygen containing atmosphere is larger than that in non-oxygen; activation energies which were calculated by iso-conversional methods, the value in oxygen obeyed a wavy tendency with oxygen concentration were larger than that in oxygen-free oxygen for the co-effect of oxidation and termination of radical mechanism propagation and the average values were 126.38, 176.45, 146.56, 200.01 $\mathrm{Kj} / \mathrm{mol}$ at the concentration of $0,20,50,80 \mathrm{vol}$. $\%$.

\section{REFERENCES}

1. M.K. Jain and A.S. Abhiraman, J. Mater. Sci., 22, 278 (1987).

2. D. Zhang and Q. Sun, J. Appl. Polym. Sci., 62, 367 (1996).

3. A.K. Gupta, D.K. Paliwal and P. Bajaj, J. Macromol. Sci. C: Polym. Rev., C31, 48 (1991).

4. R. Devasia, C.P.R. Nair, R. Sadhana, N.S. Babu and K.N. Ninan, J. Appl. Polym. Sci., 100, 3055 (2006).

5. Q. Xu, L. Xu, W. Cao and S. Wu, Polym. Adv. Technol., 16, 642 (2005).

6. J.C. Chen and I.R. Harrison, Carbon, 40, 25 (2002).

7. J.X. Z, X. Xu, L.H. Xu and Y.Q. Dai, Polymer (Korea), 32, 150 (2008).

8. Y.M. Hitoshi, S. Yamazaki and K. Kamide, Polym. J., 23, 765 (1991).

9. A.J. Wan and C.X. Zhao, Polym. Mater. Sci. Eng., 17, 48 (2010).

10. C.X. Wu, A.J. Wan and J.X. Zhao, Synth. Technol. Appl., 15, 1 (2000).

11. S. Dalton, F. Heatley and P.M. Budd, Polymer, 40, 5531 (1999).

12. T.-H. Ko, H.-Y. Ting and C.-H. Lin, J. Appl. Polym. Sci., 35, 631 (1988).

13. E. Fitzer and D.J. Müller, Carbon, 13, 63 (1975).

14. K.-I. Morita, H. Miyachi and T. Hiramatsu, Carbon, 19, 11 (1981).

15. G.L. Collins, N.W. Thomas and G.E. Williams, Carbon, 26, 671 (1988).

16. L.A. Beltz and R.R. Gustafson, Carbon, 34, 561 (1996).

17. K. Kamide, H. Ono and K. Histatani, Polym. J., 24, 917 (1992).

18. H. Ono, K. Hisatani and K. Kamide, Polym. J., 25, 245 (1993).

19. Z. Wangxi, L. Jie and W. Gang, Carbon, 41, 2805 (2003).

20. P. Bajaj, T.V. Sreekumar and K. Sen, J. Appl. Polym. Sci., 79, 1640 (2001).

21. N. Grassie and R. McGuchan, Eur. Polym. J., 7, 1357 (1971).

22. J.B. Donnet and R.C. Bansal, Carbon Fibers, Marcel Dekker, New York, edn. 2, pp. 1-82 (1990).

23. T. Ozawa, Bull. Chem. Soc. Japan, 38, 1881 (1965).

24. J.H. Flynn and L.A. Wall, J. Polym. Sci. B: Polym. Lett., 4, 323 (1966).

25. H.E. Kissinger, Anal. Chem., 29, 1702 (1957).

26. S. Tiptipakorn, S. Damrongsakkul, S. Ando, K. Hemvichian and S. Rimdusit, Polym. Degrad. Stab., 92, 1265 (2007).

27. S.P. Zou, Y.L. Wu, M.D. Yang, C. Li and J.M. Tong, Bioresour. Technol., 101, 359 (2010).

28. H.N. Friedlander, L.H. Peebles Jr., J. Brandrup and J.R. Kirby, Macromolecules, 1, 79 (1968).

29. W. Watt and W. Johnson, Nature, 257, 210 (1975). 